\title{
HOW FREQUENTLY CAN WE PREDICT FAILURE OF FLUID RESTRICTION IN SIAD? RESULTS OF A MULTICENTER PROSPECTIVE AUDIT
}

Martín Cuesta, Ana Ortolá1, Aoife Garrahy, David Slattery, William Tormey, Alfonso Luis Calle-Pascual'1, Isabelle Runkle'1, Christopher J Thompson. Beaumont Hospital, Dublin, Ireland . ${ }^{1}$ Hospital Clínico San Carlos, Madrid, Spain

\section{Introduction}

The commonest cause of hyponatraemia in clinical practice is the Syndrome of Inappropriate Antidiuresis(SIAD). Clinical guidelines from the USA and Europe are consistent in their recommendation that fluid restriction should be first line therapy if hyponatraemia in SIAD requires intervention ${ }^{1,2}$. However, the evidence base for the use of fluid restriction is very limited ${ }^{1}$, with no randomized controlled trials in SIAD to support the recommendations. In addition, fluid restriction is difficult to implement, particularly if patients require intravenous antibiotics or nutritional supplementation, and many patients are unable to tolerate the degree of restriction of fluid intake that is necessary to elevate plasma sodium concentration.

The US guidelines included useful predictors of non-response to fluid restriction, including urine osmolality $>500 \mathrm{mOsm} / \mathrm{kg}$, urine output $<$ $1500 \mathrm{ml} / 24 \mathrm{~h}$ and Furst equation ratio(urine sodium + potassium/plasma sodium) $>1$

\section{Objective}

We set out to determine how many patients had pre-treatment criteria which would predict failure of fluid restriction in a non-selected population of patients with well-defined SIAD.

\section{Material and methods}

183 patients were consecutively recruited in Hospital Clínico San Carlos, Madrid $(\mathrm{n}=51)$ and Beaumont Hospital, Dublin $(\mathrm{n}=132)$ with a diagnosis of SIAD. Full ascertainment of the diagnostic criteria for SIAD was obtained with $100 \%$ of patients having appropriate results for urine osmolality and urine sodium concentration, normal thyroid function and $0900 \mathrm{~h}$ cortisol $>300 \mathrm{nmol} / 1(>10.9$ $\mathrm{mcg} / \mathrm{dl})$.

Basic clinical data to predict failure to respond to fluid restriction was obtained but clinical decisions were left to admitting physicians.

\section{Results}

Median age was 75 years (IQR 64,82), 109(59\%) were female.

The most common causes of SIAD were central nervous disorders $(\mathrm{n}=38$, $20.9 \%)$, pulmonary diseases $(n=36,19.8 \%)$, malignancy $(n=36,19.8 \%)$ and drugs $(\mathrm{n}=16,8.8 \%)$.

\begin{tabular}{|l|c|c|}
\hline PREDICTOR OF FAILURE OF FLUID & N & $\%$ \\
\hline RESTRICTION & $49 / 103$ & 47 \\
\hline Urine volume $<1500 \mathrm{ml} / 24 \mathrm{~h}$ & $75 / 183$ & 41 \\
\hline Urine osmolality $>500 \mathrm{mOsm} / \mathrm{kg}$ & $48 / 183$ & 26 \\
\hline Furst equation ratio $>1$ & $109 / 183$ & 59 \\
\hline Presence of one predictor & $69 / 183$ & 37 \\
\hline Presence of two predictors & $6 / 183$ & 3 \\
\hline Presence of three predictors & \\
\hline
\end{tabular}

Our data demonstrate that a significant proportion of a well-defined prospective and consecutive cohort of SIAD patients had clinical parameters that the US guidelines would suggest could predict failure of response to fluid restriction.

$59 \%$ of patients had one criterion and $37 \%$ of patients had two predictors.

The sensitivity and specificity of the predictors of failure remain unpublished. However, if the predictors are accepted as correct, our data suggest that up to $60 \%$ of patients with SIAD could be predicted to be non-responders to fluid restriction, the universally-recommended first line therapy for SIAD. This would suggest that a trial testing the validity of the predictors of failure would provide important information; if the predictors of failure of response to fluid restrictors are shown to be accurate, the role of fluid restriction as first line therapy for SIAD should be re-assessed, if over $50 \%$ of patients can be predicted to fail to respond to therapy.

\section{References}

1. Verbalis JG, Goldsmith SR, Greenberg A, et al. Diagnosis, evaluation, and treatment of hyponatremia: expert panel recommendations. Am J Med. 2013; 126: $1-42$.

2. Spasovski G, Vanholder R, Allolio B, et al. Clinical practice guideline on diagnosis and treatment of hyponatraemia. Eur J Endocrinol. 2014; 170: 1-47 